\title{
La construcción equipada del vínculo amoroso. Las webs de encuentros y sus «caminos de confianza»
}

\author{
Johann Chaulet, Université Toulouse le Mirail, LISST CERS ${ }^{1}$
}

\begin{abstract}
Resumen
El artículo pretende abordar la manera en que la confianza se instala progresivamente entre dos desconocidos puestos en relación en una página web de encuentros amorosos. Estudiando en detalle la progresión de las "trayectorias de confianza", podemos comprender cómo los usuarios identifican las propiedades específicas de los distintos dispositivos de comunicación para ir franqueando las etapas de la confianza. El dispositivo que permite iniciar la relación es completado gracias a nuevas mediaciones que dan acceso a información nueva. Esta gestión prudente de la relación y de su progresión se apoya en la complementariedad de las herramientas que permiten saber más y más sobre el Otro. Si el proceso es exitoso, se producirá el encuentro físico y la confrontación de los cuerpos.
\end{abstract}

Palabras clave: Páginas de encuentros, mediación, confianza, comunicación.

\section{Résumé}

L'article présenté ici entend traiter de la façon dont la confiance se met progressivement en place entre deux inconnus mis en relation sur un site de rencontre amoureuse. Etudiant en détail la progression des «parcours de confiance», nous pourrons comprendre comment les propriétés spécifiques des différents dispositifs de communication sont identifiées par les utilisateurs pour leur permettre de franchir peu à peu les étapes de la confiance. Le dispositif ayant permis d'initier la relation se verra complété de nouvelles médiations offrant l'accès à de nouvelles informations. Cette gestion prudente de la relation et de sa progression repose sur la complémentarité des outils qui permettent d'en savoir toujours plus sur l'Autre permettant à terme la rencontre physique et à la confrontation des corps.

Mots clé: Sites de mise en relation, mediation, confiance, communication.

\begin{abstract}
This article intends to explore the way in which trust progressively emerges between two unknown people who meet in a website to find love relationships. By studying in detail the progression of "trust trajectories", we will be able to understand how users identify specific properties of media to progressively install trust. Media allowing for a first contact will be completed by the use of other media allowing to access new information. This wise management of the relation and its progression relies on the complementarities of tools allowing to know more and more about the Other. If the process is successful it will lead to a physical meeting and to the confrontation of bodies.
\end{abstract}

Key words: Websites for relationships, mediations, trust, communication.

\footnotetext{
${ }^{1}$ Enviar correspondencia a: chaulet@univ-tlse2.fr.
} 
El estudio empírico que ha permitido la elaboración de los resultados expuestos aquí, pretenden explorar los procesos de confianza en juego en el campo de las comunicaciones mediatizadas. En este artículo nos vamos a centrar únicamente en la parte de nuestro trabajo sobre las webs de encuentros de pareja. Estas webs presentan numerosos aspectos interesantes cuando se trata de abarcar las relaciones de confianza "mediatizadas". Para empezar, estos portales introducen en relaciones a personas que no se conocen en absoluto. Centradas por la búsqueda de un objetivo (preciso y explícito en distintos grados) requieren depositar una confianza mínima para que se puedan alcanzar los objetivos comunes que se han fijado los actores. Este objetivo de establecer una relación definida a priori (al menos en parte) como veremos más adelante, influye enormemente en las modalidades de contacto y la forma en que las relaciones comienzan, y en ocasiones continúan adelante. Las lógicas de eficacia y de rentabilidad imprimen usos que parecen ser un lugar propicio para poner a prueba una hipótesis de racionalización de las prácticas de comunicación, así como las prácticas relacionales.

Si bien en tales entornos no se inician procesos de búsqueda "racional" del conjunto, sus modos de funcionamiento y las reapropiaciones de los usuarios hacen que sean lugares particularmente pertinentes para estudiar la forma en que la confianza se va apoyando en la tecnología, y las posibilidades que ofrece a los actores de gestionar la progresión de las relaciones. No querríamos dar a entender que la relación amorosa que se pondrá en marcha se limita a la construcción de una cuestión de confianza. Por supuesto no basta con tener confianza para enamorarse. Sin embargo, y precisamente porque las personas en sus propios contextos son perfectas desconocidas entre ellas, parece indispensable un sentimiento de confianza mínimo para poder conseguir tal objetivo. Ciertamente, la confianza no es el único "ingrediente" a tomar en cuenta cuando se trata de hablar del sentimiento amoroso y de su creación, no obstante, es en ella en la que nos vamos a centrar en nuestro análisis.

el Los resultados expuestos aquí son el fruto de un estudio empírico utilizando fuentes heterogéneas y complementarias. La realización de entrevistas semi directas nos ha permitido extraer los puntos esenciales de nuestro análisis en cuanto a las representaciones de usuarios en estas webs, y comprender en concreto cómo se construyen las formas de confianza que nos interesan. Las personas con las que hemos contado para estudio forman parte de nuestro entorno personal, en primer o segundo grado. La relación de intimidad particular que nos 
vincula a algunos de los entrevistados nos ha permitido tener acceso a ciertas conversaciones escritas cuyas transcripciones se nos han proporcionado. Asimismo, nuestro análisis se ha completado por la lectura de los blogs de estos usuarios: uno de los dos principales actualizó su contenido de forma muy regular durante tres años, y el otro durante dos años. Estos "relatos de vida" autobiográficos y a menudo anónimos, ofrecen al sociólogo una ventana hacia la intimidad y las reflexiones de los usuarios que se entregan a tales prácticas reflexivas sobre su actividad y sobre las relaciones que desarrollan a través de la utilización de estos servicios. Para escribir, el bloguero debe hacer un esfuerzo de coherencia similar a la que impone una entrevista; no obstante, dispone de un tiempo confortable para describir de forma precisa sus estados de ánimo o sus pensamientos. Estos textos son para nosotros una oportunidad de desarrollar análisis de datos importantes, acumulados tras periodos bastante más largos de lo que nuestras investigaciones nos permiten seguir. De hecho, la utilización de tal fuente es inadecuada para establecer hechos históricos, en cambio sí es apropiada cuando se trata de estudiar "un ejemplo de un actor que experimenta un proceso de formación y de reformación de expectativas sobre otro actor" ${ }^{2}$, que es precisamente la cuestión que nos interesa.

De lo que se trata, en estos marcos específicos de interacción es de asegurar el paso del estatus de desconocido al de "pareja". El hecho de que la pareja potencial sea un desconocido genera un déficit de informaciones, y por lo tanto cierto riesgo e incertidumbre ${ }^{3}$, ya que los actores no pueden formular ninguna inferencia en cuanto a su identidad y a las motivaciones de la persona con la que consideran iniciar una relación. Cuando los actores se encaminan hacia este modo de inicio de una relación indica que ambos asumen el riesgo que conlleva, al menos en parte, lo que no significa que este riesgo esté menos presente. Estas nociones de riesgo, incertidumbre, e información son temas centrales cuando se trata de la confianza. El contacto y las informaciones que éste proporciona, la distancia física, así como el proceso de acercamiento físico eventual, hacen de este terreno un elemento de peso a la hora de adquirir conocimientos sobre las relaciones de confianza en el ámbito de la comunicación mediatizada y, en mayor medida, sobre la construcción equipada de las relaciones sociales, ya sean permanentes o efímeras. Así pues, aquí nos vamos a centrar en el marco del desarrollo de las relaciones a distancia, a poner en marcha el programa que Simmel anheló a principios del siglo pasado, es

\footnotetext{
${ }^{2}$ Möllering, 2005, p.289 (traducción personal).
} 
decir, proceder a "un estudio especializado para determinar qué tipo y qué grado de conocimiento recíproco son necesarios en las diferentes relaciones entre las personas" . Sztompka afirma que internet constituye "una nueva era donde los dilemas del anonimato como limitador de confianza aparecen particularmente con fuerza." ${ }^{\prime 5}$ Sin embargo, veremos cómo los actores intentan superar el riesgo y la incertidumbre para alcanzar un objetivo común (cosa que consiguen con más o menos éxito) empleando los medios tecnológicos que manejan activamente. Examinar estos "caminos de confianza", mejor o peor equipados, nos permitirá comprender la manera en la que las herramientas que median los contactos se convierten para los actores en los instrumentos concretos de la construcción de la confianza, y más adelante, de la relación con el otro.

Si bien algunos "momentos" de la relación merecen que nos detengamos, lo que no nos interesa aquí es todo lo que precede al contacto entre los usuarios de los portales de encuentros. Nos apoyaremos en nuestro trabajo empírico para afirmar que el entorno impone la forma de presentarse, y que equipa las relaciones entre usuarios en general y las relaciones de confianza en particular, definiendo a priori el papel de cada cual y legitimando actitudes. Preferimos detenernos en el momento preciso del contacto y del inicio de la relación. Estudiaremos pues las modalidades de contacto y la elaboración concreta de los caminos de confianza por medio de entrevistas elaboradas a los usuarios de las webs de encuentros o de extractos de los blogs de dichos usuarios. Las relaciones abandonarán el anonimato que las caracteriza inicialmente, y se producirán juicios y calificaciones de manera personalizada, especialmente gracias al aumento de las formas de contacto. Veremos cómo se cierran estos recorridos esforzándonos por comprender cómo la reflexión, las generalizaciones, y la experiencia de los usuarios influyen más o menos directamente en su forma de actuar y de interactuar en el entorno de las relaciones específicas. Finalmente, el lector podrá comprender cómo se da una relación de confianza en un medio donde podría echarse en falta; podrá entender la forma en la que los mediadores interrelacionales permiten activar una lógica de prudencia, entregándose al otro de manera inevitablemente controlada; en adelante, será capaz de comprender lo que de manera evidente parece estar en juego según las modas contemporáneas de sociabilidad y de comienzos de relaciones.

\footnotetext{
${ }^{3}$ Fernandez, 2003 ; Gomez, Korrine \& Masclef, 2003 ; Nooteboom, 2006.

${ }^{4}$ Simmel, 1999, p.348.

${ }^{5}$ Sztompka, 1999, p.82.
} 


\section{Las herramientas como estructuración y visualización de las etapas}

Tal como muestran los estudios efectuados sobre la construcción de la confianza entre empresas ${ }^{6}$, constatamos que los caminos de los que nos vamos a ocupar aquí implican a su vez tiempo, validaciones sucesivas y repetidas, juicios de confirmación y modos de calificación heterogéneos. La búsqueda del vínculo a menudo no es tácita, como escribe Allan ${ }^{7}$. El momento particular del descubrimiento así como el carácter objetivante de las herramientas y los pasos que median, conducen ciertamente a preferir una visión más reflexiva y reflexionada del inicio del proceso y de la búsqueda del vínculo. En los procesos de desarrollo siguientes vamos a estudiar cómo la tecnología y las diversas clasificaciones que los actores utilizan en el entorno de su "universo de comunicación", mediatizado o no, forman parte de esta gestión de los compromisos y del camino de confianza que construyen poco a poco con sus parejas, especialmente llevando a cabo las etapas que hay que franquear una tras otra.

Aunque no vamos a detallar aquí estos procesos, debemos insistir brevemente en la importancia de la reciprocidad en los procesos de inicio de la relación. Así pues, la reciprocidad o la "equidad" 8 aparecen como elementos centrales en la construcción progresiva de una relación de confianza, más aún cuando ésta implica a personas desconocidas entre sí y que por lo tanto no poseen conocimiento alguno del otro que pueda condicionar una opinión. La reciprocidad aparece entonces como la solución para permitir la construcción de una confianza sin bases. "Se supone que la idea de que exista un instinto de reciprocidad debe aportar una solución a un problema recurrente: el de saber cómo entablar una relación en ausencia total de todo fundamento de confianza previa"'. Uno acepta más comprometerse si su pareja acepta un compromiso al menos equivalente. En efecto, Trompette recurre a las nociones clásicas de don y contra-don para explicar que "dar su palabra, o a la inversa, conceder su confianza, es precisamente activar una norma de reciprocidad"10. Así, "el paradigma de la reciprocidad hace del don un acto de compromiso"11. El don en este contexto puede tomar formas simbólicas muy diferentes; notemos que la apertura de los entornos íntimos y privados se cuenta

\footnotetext{
${ }^{6}$ Podemos citar como ejemplos: Gomez, Korrine \& Masclef, 2003 ; Lorenz 1996 ; Nooteboom, 2006 ; Trompette, 2003.

${ }^{7}$ Allan, 1979.

${ }^{8}$ Blau, 1964.

${ }^{9}$ Nooteboom, 2006, p.84.

10 Trompette, 2003, p.104

11 Ibid., p.107.
} 
entre los signos importantes de un compromiso suplementario. Entregarse, decirse y dejarse descubrir sabiendo empatizar ${ }^{12}$, dejando al otro la posibilidad de ocupar un lugar cada vez mayor en su vida, son otras de las formas de demostrar un compromiso creciente. La reciprocidad del compromiso debe pues encontrar medios de expresión adaptados a cada forma de contacto y a sus códigos particulares.

La confianza consiste esencialmente, según Luhmann, en un proceso de reducción de la complejidad. Cuando habla de la confianza interpersonal y de su construcción progresiva, el sociólogo explica que "la cuestión de la emergencia de la consolidación de la confianza personal nos da la posibilidad de trasladar a la dimensión temporal el problema de la reducción de la complejidad (...) y mostrar así que se puede resolver de una manera gradual por medio de la formación de relación de confianza. El "principio de los pequeños pasos" reemplaza las formas más simples de adaptación al entorno, allí donde el entorno actúa también de manera contingente o incluso donde es demasiado complejo para una adaptación instantánea."13 Para Luhmann, el comienzo progresivo de esta confianza implica la efectividad de estas etapas que permiten estructurar lo que llamamos aquí un camino de confianza. El autor afirma que "una de las condiciones previas es que en general la situación admita etapas selectivas a modo de poder modificar el comportamiento, es decir, que no esté ya fijado institucional o históricamente"14. Estas etapas existen debido a que los usuarios, en el ámbito en el que las emplean, se preocupan de darles uso, de hacerlas visibles y de darles sentido. Veremos que si bien existen ciertas etapas de manera general, no son fijas, ni estables ni inamovibles, sino al contrario, cada pareja las personaliza y las negocia a lo largo de la construcción de la relación. Veremos de manera efectiva y concreta hasta qué punto estas etapas desempeñan un papel esencial en la progresión de la relación.

Entre los elementos que merecen ser evidenciados, se encuentra la temporalidad de las relaciones, que es un elemento particularmente problemático en cuanto a la gestión y la construcción de los caminos relacionales que nos interesan aquí. Saber cuál es el "momento adecuado" para llevar a la relación hacia un rumbo u otro (especialmente teniendo en cuenta las aspiraciones que esto pueda conllevar) parece ser para ambos integrantes de la pareja una incógnita recurrente. Además, el paso de una etapa a otra genera una aprensión relacionada con temores, y con

\footnotetext{
12 Feng, Lazar \& Preece, 2004.

${ }^{13}$ Luhmann, 2006, p. 45.

14 Ibid., p.46.
} 
el riesgo de decepcionarse al descubrir al otro. Como dice uno de nuestros entrevistados, "sigues sintiendo temor en cada etapa". Vamos a estudiar aquí la forma en la que los actores se equipan en estos caminos dentro del contexto de relaciones relativamente imprecisas en cuanto a sus objetivos y que por lo tanto generalmente inician caminos de confianza más bien largos. Los siguientes análisis serán una ocasión de ver de manera muy significativa las rupturas concretas que efectúan los actores, así como su puesta en práctica en el entorno del comienzo de relación hacia la intimidad creciente. Cada herramienta tiene atribuida un significado en particular en cuanto a la implicación que traduce, veremos que "según la naturaleza de los contextos de comunicación, [los actores] otorgan un significado específico a cada soporte y desplazan sus contactos de un medio de comunicación a otro (...). La historia de cada relación se apoya sucesiva o paralelamente sobre los distintos soportes, y cada uno se utiliza con un significado específico en la gestión de las relaciones. Cuanto más íntima es la relación, más se multiplican las herramientas empleadas en ella"15.

Así que no sé si debo o no, proponerle ya que nos encontremos en persona (aunque no sé si tengo que decir "ya" o "por fin"). En nuestras charlas, aunque son frecuentes y preciadas, nunca abordamos lo que nos relaciona: el potencial idilio. Nos quedamos muy lejos de lo que esperamos el uno del otro. Pero tengo la sensación de que nuestro encuentro en internet hoy ha alcanzado un tope y tiene que encontrar un nuevo terreno para evolucionar en el encuentro real (extracto del blog de Anadema).

Nuestro propósito se construirá en torno a un recorrido ideal típico. Este recorrido no pretende generalizar al conjunto de relaciones que se inician a través de portales de encuentros, pero sí es cierto que cada una de las etapas detalladas aquí se construye a partir de observaciones y representaciones desarrolladas en el contexto de los usos que, por su comprensión, ganan al ser reagrupadas bajo esta forma específica. El continuum que dibujamos aquí no es el universal, pero aparece de manera más frecuente al comienzo de las relaciones que nos interesan. Las formas de este recorrido así como los encadenamientos precisos entre las diferentes herramientas, pueden adoptar formas diversas y variadas en función de las representaciones individuales en cuanto a uno o a otro. Por ello, puede ser importante precisar que más que las herramientas específicas que equipan estos

${ }^{15}$ Cardon, Smoreda \& Beaudouin, 2005, p.112. 
pasos, se trata de subrayar el proceso de utilización de los límites y su uso en la medida en la que esto permite a los usuarios un dominio sobre las relaciones así como una visualización y una objetivación de su "estado".

Es un sistema de etapas: empiezas por el correo electrónico y cuando sientes que realmente hay algo que se asienta, decides pasar a la etapa siguiente, el teléfono, porque la voz ya es otra cosa, porque ... oír a alguien hablar, las expresiones, la velocidad del lenguaje, la entonación, eso te dice mucho más que un e-mail, conque eso te da más información todavía y después pasas a la etapa siguiente en la que... para mí era de cajón, vamos (...), lo tenía clarísimo (Brigitte).

Se verá mucho más claro a medida que se detallen las diferentes etapas de las que está compuesto el camino de confianza; no obstante encarta introducir desde ahora el esquema siguiente, ilustrando la noción de camino llevando a cabo los pasos entre diferentes formas de contacto y "zonas" correspondientes. Las cifras que aparecen en este esquema corresponden a los diferentes pasos que vamos a estudiar y a las tres primeras partes de nuestro desarrollo.

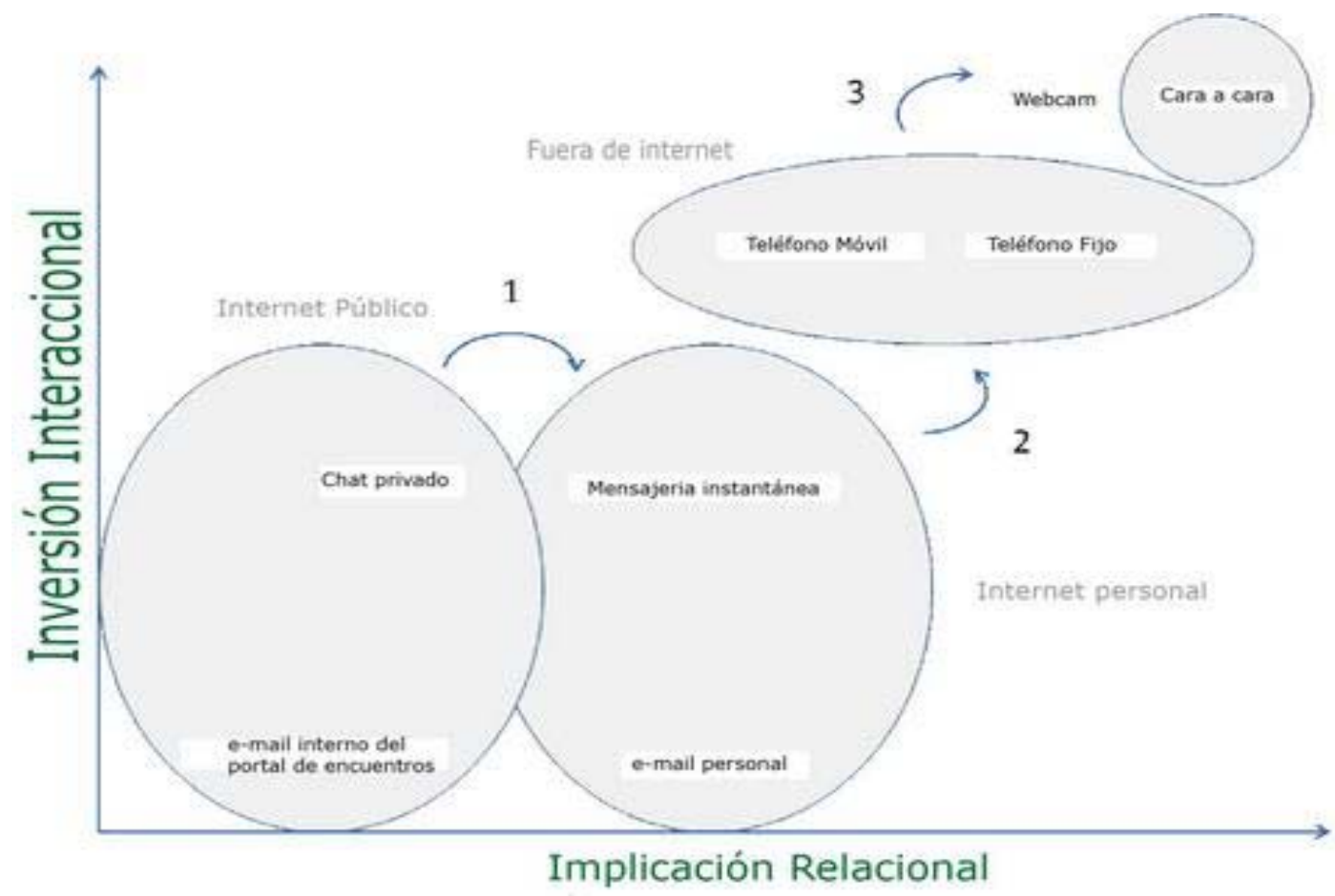

I lustración 1. Camino de confianza y sucesión de contactos.

El sentimiento de confianza, que es al mismo tiempo causa y consecuencia, ocupará aquí un lugar doble: la gestión equipada del camino y el "derecho de entrada". La confianza es la razón por la que se conceden estos "derechos de 
entrada" (el extracto de la entrevista siguiente representa una formulación particularmente elocuente de este proceso). También es el resultado de nuevos encuentros, ya que la multiplicación de contactos permite tener acceso a ellos. $\mathrm{Si}$ los actores saben lo suficiente sobre el otro y esos conocimientos legitiman un comienzo, deciden dejarle entrar en un territorio nuevo que una vez explorado les permite obtener nuevas informaciones sobre el otro y solidifican la confianza (o la cuestionan) ampliando el registro de conocimientos sobre los que dicha confianza se apoya.

Hay uno al que le abrí las puertas totalmente. En el momento en que... realmente tuve confianza, eh..., ahí mismo me solté. Total, que le dejé entrar (Brigitte).

Como explica Illouz, "la escena clásica es la siguiente: la gente consulta una lista de parejas potenciales y decide entrar en contacto por e-mail con una de ellas fiándose de la foto y del perfil de la persona en cuestión. Cuando todo va bien, comienzan a fantasear con una futura cita. Este sentimiento les conduce a tener primero una conversación telefónica. Mucha gente, por no decir todo el mundo, declaran que cuando la voz de la persona les gusta, pueden empezar a alimentar fuertes sentimientos por esa persona"16. Vamos a completar esta descripción y detallar los significados y las representaciones que acompañan los pasos de una forma de contacto a otra. Es pertinente introducir esta descripción detallada en las reflexiones de una de nuestras entrevistadas que explica la influencia de las formas de contacto sobre el desarrollo de las relaciones y las impresiones producidas en los interlocutores. Esta descripción resume numerosos puntos que tendremos que desarrollar, ya que ilustra el hecho de que la evolución de los contactos y de las informaciones que proporcionan desempeña un papel importante en las posibilidades de engaño. En este sentido reúne todo lo que está en juego según Donath en cuanto a la dificultad que presentan los contactos mediatizados por el trabajo de construcción de la identidad de la persona con la que se hace el contacto. ${ }^{17}$ Los engaños son más difíciles de llevar a cabo cuando aumentan la cantidad de información y su naturaleza. Como veremos más adelante, el aumento de las formas de contacto va acompañado de un aumento de la implicación, un conocimiento más afinado del otro y una posibilidad de engaño disminuida. El engaño siempre será más fácil de llevar a cabo en el entorno de contactos

\footnotetext{
${ }^{16}$ Illouz, 2006, p. 258.

${ }^{17}$ Donath, 2003.
} 
mediatizados que en una situación de cara a cara (donde aun así sigue estando presente, por supuesto). Se requiere tiempo y haber tenido diferentes contactos para saber "a quién tiene uno delante", pero al parecer también para tener ganas de saberlo y desear saberlo todo, tanto como que el otro sepa todo también de uno.

Es tan sencillo este tipo de sistema, no sabes con quién tratas y es muy fácil mostrar tu mejor cara. Es por escrito, de mail a mail, conque no es instantáneo (...) Así que es tan sencillo tocarle la fibra al otro que hace falta mucho más tiempo para llegar a descubrir a quién tienes delante. (Brigitte).

\section{Salir de la web: personalización de una zona anónima}

Después de pasar cierto tiempo hablando por el chat del portal de encuentros, es habitual que las personas intercambien sus direcciones de mensajería instantánea. Con ello, por un lado se ofrecen la posibilidad de salir de un espacio de diálogo que a nivel técnico es con frecuencia inestable (disminuyen pues las posibilidades de que se cierre la conversación de manera repentina y que el otro desaparezca), y por otro lado, multiplicar las posibilidades de encontrarse, de cruzarse (a diferencia de las zonas de chat de las webs, los programas de mensajería instantánea suelen abrirse automáticamente en cuanto el ordenador se conecta a internet y entonces aumentan las posibilidades de "cruzarse" en la red). La relación atraviesa una primera fase de autonomización al salir del contexto inicial de formación y se distingue así del conjunto de las que todavía siguen confinadas. Dar la dirección del messenger significa permitir al otro el acceso a un espacio más personal y más personalizado que su espacio de contacto mediático. El riesgo está controlado, ya que los usuarios cuentan con la posibilidad de "bloquear" en cualquier momento a los contactos que puedan volverse molestos. Otra forma de autonomización dentro de la "zona internet" es dar la dirección de correo electrónico personal y no volver a utilizar el sistema de correo del portal de encuentros para establecer contacto. Permanecer en una sola zona significa poner distancia, mientras que la multiplicación de "entornos" de contacto implica acercamiento. Esta gestión de los derechos de entrada equipa a la gestión de la intimidad en la medida en la que se ve el avance de la relación y el estatus particular del cual se benefician los que se conceden esta primera forma de privilegio.

Le he mandado mi dirección de correo electrónico personal. Eh... que sólo le he dado a ella. Y bueno, pues... es cierto que tampoco es algo 
que tenga una importancia extrema para... para todo el mundo, pero para mí sí la tiene. No todo el mundo tiene mi e-mail. (Óscar, 28 años, asalariado, usuario de Meetic).

Aunque los riesgos están todavía ampliamente controlados y son controlables, el hecho de pasar de un entorno abierto de interacción a un espacio donde los interlocutores se escogen y seleccionan voluntariamente, procede aun así de un primer paso de compromiso. Este trámite constituirá pues la primera etapa del camino de confianza. El cambio de tipo de contacto también va a la par de cierta focalización de la atención sobre una o varias interacciones privilegiadas, dependiendo de la multitud de contactos ofertados por las webs empleadas. Este paso proporciona en cierta forma una exclusividad de los compromisos cuando se aprecia la atención particular que unos le dedican y otros no. Por otro lado, estos pasos están fuertemente negociados y conllevan con frecuencia comportamientos estratégicos por parte de los actores, tal y como nos lo muestran los testimonios a continuación. El desequilibrio importante del número de inscritos de un sexo y otro, por ejemplo, coloca por lo general a las mujeres en situación de control. Al estar muy solicitadas, son ellas las que tienen que gestionar la "masa" de contactos. La iniciativa parece ser un elemento problemático, y numerosos usuarios masculinos declaran dejar la iniciativa a la otra parte a la hora de cruzar una etapa suplementaria a la relación, con tal de no arriesgarse a un rechazo al plantear ese nuevo paso o al desvelar sus intenciones al respecto, y ver entonces su impaciencia castigada por poner en peligro la relación que apenas empieza.

Tenía charlas interesantes incluso aunque no les diera continuidad, o sea, si no les daba mi dirección... El Messenger para mí es eso, dar continuidad a algo; es no quedarse en el chat de Meetic, sino pasar a otro... pasar a otro nivel (...) a partir del momento en el que... no es una cuestión de confianza, pero cuando no llegaba a captar a la persona, me quedaba en el chat de Meetic (Marie, 22 años, estudiante, usuaria de Meetic).

Ahh, ese detalle que te atormenta tan a menudo, mira, si te he abierto esta puertita a mi correo electrónico, es porque he querido dejarte entrar... no se puede decir que "lo haga a menudo"... pues no, no, nada de nada, no me molestas... idiota 
En el chat, no te quedarás eternamente. Te encasillas y luego vuelves a salir. Si eres muy bueno, en el $99 \%$ de los casos será ella quien te proponga pasar al Messenger, que es el segundo paso de la Gran Escalera de la seducción ON LINE. Después, ya es cosa tuya pedirle el teléfono o quedar en una cita inmediata si sientes que ella lo busca. No olvides dejar que sea ella la que pida. Tú eres el Premio (copyright de Spike). Recuérdalo bien, lector (Kamikaze, en la página web de Spikeseduction).

Al principio hay mucho chateo con una afinidad que se crea, de verdad que es muy amistoso al principio. Además, es... eh... antes no había Messenger, ahora nos lanzamos rápidamente al Messenger porque es mucho más práctico con la gente que yo quiero, porque ahora todos tienen tendencia a pedirme mi dirección de Messenger, pero no la doy (Zoé, 25 años, estudiante, usuaria de Meetic).

\section{Salir de la red: poner los pies en la "realidad"}

El contacto sin embargo, queda por el momento relegado a la "zona" internet y la relación es únicamente por escrito. Examinemos ahora cómo se produce y se gestiona la "salida de la red", forma simbólica suplementaria de progresión de la relación.

Tras algunas horas de conversaciones a través de los programas informáticos de mensajería instantánea, los actores intercambian entre ellos sus números de teléfono móvil, siendo el móvil una herramienta de comunicación personal en sí mismo. Seguidamente se inician las primeras comunicaciones de voz y los primeros contactos por mensajes de texto. Antes de oírse, los móviles permiten intercambiar sms ofreciendo al actor la seguridad del texto escrito, ofreciendo a su vez una posibilidad de contacto casi constante y totalmente autónoma de la herramienta informática y de la conexión a internet. Al requerirse una inversión interaccional mínima, y los mensajes de texto son un medio de invertir más en la vida del otro sin arriesgarse invirtiendo demasiado de uno mismo en el contacto. Por ello, "en general el sms es con frecuencia el paso intermedio entre el Messenger y la llamada telefónica" (Pierre). El extracto siguiente es particularmente importante para ilustrar la estructura de las etapas y el papel que recae sobre las herramientas en el contexto de estos caminos. 
Media hora más tarde, nos llamamos. Se acabó el tiempo en el que me cuidaba de dar mi número a desconocidos. Cuando el tío me inspira confianza, prefiero que nos llamemos antes de encontrarnos, para no perder el tiempo si hay algún mal rollo por teléfono. Así que les hago pasar primero el examen escrito y luego el oral, y después se ganan el derecho a quedar con el jurado, lo que en jerga de oposiciones del Ministerio de Educación Ilamamos "el confesionario!" (Saskia, profesora de francés, usuaria de Meetic).

Aquí vemos cómo los pasos de diferentes formas de contacto constituyen para Saskia un auténtico método de gestión de las relaciones que se someten a diferentes "pruebas". Parece en efecto que la construcción de una relación de confianza con uno o varios desconocidos requiere emplear estas pruebas que permiten testear cuán bien fundada está la progresión de la relación y el compromiso con su compañero. Tal y como escriben Guillaume y Uhalde, "la noción de prueba nos reenvía a una definición de procedimiento y experiencia respecto a la confianza (...) Subraya el carácter profundamente interactivo del juicio de confianza. Así pues, la relación de confianza está fundada sobre las experiencias pasadas (Lorenz 1996), y no sobre las previsiones o anticipaciones. Se basa en una evaluación continua a raíz de las nuevas experiencias. Se trata de una relación construida por los actores a razón de la eficacia y del sentido que ella confiera a la acción de ambos integrantes. En consecuencia, la confianza se gestiona, demanda señales de fiabilidad y esfuerzos, compromisos (Koenig, 1999) ${ }^{18}$. Así, acumular las formas de contacto significa igualmente acumular las formas de contacto y los juicios y permitirse la posibilidad de asegurar esta "evaluación continua" que parece imponer el descubrimiento de un desconocido y la construcción progresiva de la confianza. Las interacciones sucesivas proporcionan nuevas informaciones y permiten actualizar constantemente el juicio, mientras que los contactos siguientes le aportan nuevas formas de adquisiciones, más completas y más ricas.

Si la percepción del riesgo relacionando con el intercambio de números de teléfono parece disminuir con la experiencia, éste nunca desaparece del todo, y si bien algunos dan su número con facilidad, otros en cambio emplean directamente la gestión de los diversos derechos de entrada para poner en marcha verdaderas estrategias de protección. Los contactos escritos electrónicamente permiten finalizar una relación que se ha vuelto "molesta" de una manera bastante más fácil

${ }^{18}$ Guillaume \& Uhalde, 2003, p.51. 
de lo que sería por teléfono. Por eso Brigitte prioriza las comunicaciones por escrito a las interacciones orales, que según su experiencia pasada, representan para ella un auténtico peligro. Los comentarios de Óscar nos permiten igualmente insistir sobre el hecho de que aunque el orden ideal-típico que evocamos aquí se observa con bastante regularidad en los usos, sin embargo no es unánime. Estos pasos y las formas concretas que adoptan reposan sobre las concepciones personales que conciernen a los contactos mediatizados y a otras formas de acceso al otro, y otras maneras de conocer gente.

Tengo una historia personal que hace que no dé mi número de teléfono fácilmente a gente con la que no voy a quedar y... eh... es una forma de protegerme. Es decir, que si quiero escribir puedo hacerlo fácilmente vía e-mail, cuando es por teléfono y la persona ha decidido acosarte... ehh... no puedes hacer gran cosa, sabes... Así que es una protección (Brigitte).

Ella me ha propuesto que nos llamemos, pero para mí, no es realmente la continuación lógica de los hechos, vaya. En general, tu teléfono no lo das antes de haber visto a la persona, sabes, no sé, no es una cosa que... o muy rara vez (Óscar, 28 años, asalariado, usuario de Meetic).

Bien surja de manera fácil o bien sea problemática y peligrosa desde el punto de vista del actor, la nueva forma de contacto que constituye la conversación telefónica resulta por lo general un elemento estructurante del camino. La voz permite conocer más del otro de lo que la mera lectura de sus palabras permiten conocer y sentir. La confrontación de la voz y del tiempo real de la conversación telefónica es por lo general la última etapa antes de pasar al encuentro físico. Como nos explica Denis, "pienso que puede ser tranquilizador para ella escuchar a la persona por teléfono antes de un encuentro, le da confianza, un poquito más". Antes de poder ver al otro y de confrontar con quien es "realmente" en persona, la conversación telefónica permite cierta prueba de realidad. La voz puede tranquilizar y confirmar el sentimiento general que las conversaciones escritas permitieron crear, como también puede invalidar las impresiones iniciales y frenar el impulso de los que interactúan.

Normalmente el teléfono es el test para mí, si la voz, el estilo no me gustan, paso de quedar, no tiene vuelta de hoja (J evli, en su blog).

Presentándolo como un juego, le propuse llamarle el domingo. Me pareció una etapa transitoria muy buena entre el chat y el encuentro en 
carne y hueso: los dos ponemos un pie en la vida real del otro, también nos damos la ocasión de estar abiertos a nuevos factores humanos como el color de nuestras voces, las entonaciones, y añadir más espontaneidad en el encuentro: ¡más teclado para editar y guardar antes de enviar una frase!

Total, que me dio su número, y la llamé con un poco de aprensión, iqué nervios! :-P (Anadema)

Puedes ver la foto, ver cómo... ves las palabras en la pantalla, cómo se expresa, cómo piensa... eh... imaginas, pero la voz puede tirarlo todo por tierra, no sólo estando delante de la persona... eh... en 3D, eh... se puede caer el encanto, con la voz nada más ya se puede caer (Denis, 45 años, asalariado, usuario de Meetic).

Pues mucho chat, a menudo, y últimamente, te pasas al Messenger porque es más práctico... y en general hay al menos, al menos dos o tres... dos o tres veces en el chat antes de que haya una llamada. Tanteo un poco el terreno, si la persona me gusta o siento que me puede gustar y que es mutuo, tanteo un poco el terreno, para no dar con un pedazo de perverso o yo qué sé. Después... llamo para escuchar la voz. Por lo mismo, para saber si la voz pega un poco con lo que me ha dicho (Zoé, 25 años, estudiante, usuaria de Meetic).

Los dos últimos fragmentos nos muestran bien cómo cada uno de los pasos de una forma de contacto a otra es para el actor la ocasión de confirmar los sentimientos positivos desarrollados hasta el momento respecto al compañero. Cada uno de los pasos permite pues el arranque de una especie de "ritual de confirmación" que permite el desarrollo de conocimiento entre ellos, la confirmación de la información adquirida previamente y la formación progresiva de una intimidad compartida. Vemos bien que la voz es un elemento importante del camino, tanto para la información que proporciona como por la implicación relacional que conlleva. La importante inversión interaccional que requiere la comunicación vocal, así como las dificultades que pueden representar llevar a cabo esta interacción de presentarse uno mismo, hacen de ese momento particular un momento decisivo en la relación. Es por ello que Denis nunca está seguro de poder causar tan buena impresión a sus interlocutoras en difíciles conversaciones telefónicas, a diferencia de las largas horas de charla con los programas de mensajería instantánea. Sin embargo, esta 
etapa es generalmente un "paso obligado" para permitir a la relación su continuidad.

Es cierto que a las chicas les gusta escuchar la voz. Y resulta que a veces no he pasado la criba de la voz, lo que quiere decir que mi voz o lo que dije no gustó, porque yo me expreso bien, pero por la voz, no tengo gran cosa que decir, no tengo gran cosa que decir. Encuentro las palabras... y las escribo rápido, rrr... parece que... parece que ella piensa "escribe bien, no tiene faltas de ortografía, escribe, escribe rápido... es incluso es culto", porque me vienen un montón de ideas, pero después es otra cosa. Por la voz es completamente diferente, incluso puedo ser hasta torpe y todo (Denis, 45 años, asalariado, usuario de Meetic).

\section{Desconectar la relación: acceder a territorios concretos}

La salida de la red también pasa por la voluntad de permitir que el otro entre en los territorios de la vida cotidiana de uno. Cuando el actor comparte una relación que se está construyendo con las personas de su entorno, significa que la persona que descubre accede a una parte suplementaria de éste. La relación ya no está confinada al espacio en el que se inició y hasta el momento se mantuvo, sino que accede a las zonas concretas y físicas en las que tal vez se incluirá más adelante. Es del todo lógico ir abandonando progresivamente el medio de contacto electrónico que en su momento permitió el inicio del vínculo. Por otro lado, sucede cuando la relación entra en nuevos territorios. Estos procesos nos recuerdan mucho a las lógicas de "desanclaje" y de "enmarcamiento". ${ }^{19}$ «El desanclaje puede medirse por la capacidad de los protagonistas de contactar en ausencia del intermediario, y la capacidad de la relación de resistir a la desaparición del intermediario. Pero al mismo tiempo que la relación aparece y se desancla, ocupa su lugar en la red del otro y se enmarca. ${ }^{20}$ La "desconexión" de la relación constituye un momento específico donde ésta sale del marco y de la red de interconexión donde se inició en un principio, y el intermediario que al principio era indispensable, pierde poco a poco su peso y su importancia (desanclaje). De esta manera, la relación se autonomiza para insertarse en la vida cotidiana de la pareja y en la entorno de sus relaciones (enmarcamiento). El proceso desanclaje/enmarcamiento es pues al parecer una condición y a la vez un signo objetivo de la producción de confianza. De hecho, las declaraciones de Flore ilustran la forma en la que el hecho de hacer

${ }^{19}$ White, 1992, 2002 ; Grossetti, 2004, 2005, Grossetti \& Godart, 2007. 
pública la relación que comienza representa una objetivización particularmente importante de su implicación relacional, así como la de su pareja. Si como lo ha mostrado Ferrand, la relación amorosa muestra esencialmente un modo de coordinación "dual", independiente de las asociaciones y redes de los que interactúan ${ }^{21}$, cuando el entorno se convierte en "testigo" del idilio en formación, pesa sobre la relación que comienza ${ }^{22}$.

Pienso que si no hubiera funcionado, nos habíamos mojado bastante porque... para empezar yo ya hablaba con su hermano pequeño por el Messenger porque él le contó que había conocido a alguien. Entonces su hermano pequeño le pidió que me diera su dirección. (...) Entonces pues... nos conocimos, nos reíamos bastante y todo eso. Conque él esperaba verme en agosto en casa de su familia, y en fin... pues eso... Habríamos decepcionado a la gente, vaya (Flore, 24 años, estudiante, usuaria de Meetic).

En general me pasaba todas las noches en internet de todas maneras, jugando o cosas así. Salvo que en este caso me pasaba el tiempo hablando con ella. Al principio mis amigos se burlaban de mí, decían que era cibersexo en internet, ese era su ... era su rollo porque yo me pasaba el tiempo hablando con ella, incluso cuando ellos estaban ahí (...) incluso dejaba la ventana activa y abierta, el Messenger... la charla en el Messenger abierta. Y... pasaba la noche con mis colegas y luego volvía al Messenger cuando se marchaban. Con que lo veían sistemáticamente y veían que era... todos los días (Antoine, 29 años, asalariado, usuario de Meetic).

Esta evolución comprende desde entonces formas específicas de inversión que sobrepasan el marco inicial de contactos para "contaminar" a las otras esferas de actividad cotidiana. Así, la implicación creciente también comprende formas de inversión igualmente más importantes que ya no sólo se sitúan en el marco de las "inversiones mediáticas". Las formas de inversión vienen relacionadas con los territorios en los que se inscriben las relaciones.

\footnotetext{
${ }^{20}$ Grossetti, 2004, p.132.

${ }^{21}$ Ferrand, 2007, p.106.

22 Blau, 1964 ; Ferrand, 2007.
} 
Cuando estaba en el facultad hartaba a todo el mundo con eso, porque la conocí sabiendo que ella estaba en Polonia, y que hablaba polaco. En aquel momento empecé a tratar de aprender polaco (...) para enviarle algunas palabras en polaco, intentar un poco... gustarle, diría yo (Antoine, 29 años, asalariado, usuario de Meetic).

Esta penetración progresiva del universo desconectado de la pareja representa de igual manera la ocasión de adquirir nuevas formas de conocimiento que concreten la relación, incluso cuando sigue estando integralmente mediatizada. Saber lo que hace y lo que vive la persona con la que nos metemos en una relación permite darse cuenta de ella al mismo tiempo que la refuerza. Los actores ya no son sólo, el uno para el otro, correspondientes desconectados de todo el universo concreto , sino que se convierten poco a poco en individuos personalizados, integrados en sus actividades ordinarias. Estas formas ordinarias de conocimiento se parecen ligeramente a las formas de conocimiento desarrolladas en el entorno de relaciones desconectadas, las que se mantienen en persona. La relación sigue el mismo camino en cuanto se instalan estas formas particulares de visibilidad y de presencia a distancia.

Sabía lo que hacía a en cada momento. Pues cosas que al final uno sabe de alguien como si... eh... con ella... eh... como si viviera con ella porque pasábamos mucho tiempo juntos (Antoine, 29 años, asalariado, usuario de Meetic).

Este proceso se puede incluir en temporalidades variables. Si parece que se incluye en una temporalidad larga dentro del marco de las relaciones con implicación fuerte en las webs de encuentros, es por general bastante más rápido en el caso de la búsqueda de compañeros de piso, por ejemplo, donde el encuentro rápido señala el paso de una red a otra (de la red de la página a la de las relaciones interpersonales de nuevos compañeros de piso) y concluye el proceso. Ya que "el desanclaje se mide por la capacidad de la relación de sobrevivir a la desaparición eventual de elementos intermediarios o a la salida del grupo ${ }^{23}$, el "éxito" de este proceso se mide en la capacidad de la relación a "adaptarse" a las nuevas reglas que presiden para su mantenimiento a partir de ese momento, así como a la nueva red a la que se dirige para integrarse.

${ }^{23}$ Grossetti, 2004, p. 132. 
Yo tenía... tenía a mis amigos a mi lado, no era eh... y cuando conocía a alguien con quien me lo pasaba muy bien, pues lo integraba en mi grupo de amigos y listo (Brigitte).

Acabamos de verlo, la evolución de la implicación está fuertemente equipada por los pasos entre los diferentes formatos de contacto. De hecho existe un vínculo entre exclusividad y modalidades de contacto, ésta última visualizando una implicación particular en la relación, apela asimismo una exclusividad que no era necesaria antes del paso a la "etapa superior" (del teléfono, por ejemplo).

Durante los intercambios de mails, seguía hablando con otros. A partir del momento en el que nos llamamos, paré porque para mí... primero porque a mí me gusta tener relaciones exclusivas y yo me decía que no podía... si empiezo a tener sentimientos por él, cómo podría continuar hablando con otras personas que buscan a alguien al igual que yo, no quiero estar en esa óptica (Brigitte).

La utilización de una webcam es una etapa suplementaria y uno de los elementos que puede acercarse a lo que consideramos como "desconectado". En efecto, cuando un dispositivo es totalmente dependiente a nivel técnico de la red de internet, la visibilidad particular que introduce permite a las parejas entrar incluso indirectamente en el universo concreto y físico del/de la que se va a exponer, exponiendo una parte de su universo cotidiano. La forma en la que Antoine formula el paso de esta etapa (lejos de ser anodina, más bien al contrario), nos permite constatar hasta qué punto representa un momento realmente crucial en la relación. El uso del teléfono, y tal vez más aún el de la webcam, plantea el problema de la reaparición de los cuerpos, antes que el propio reencuentro. La cuestión del "buen momento" aquí es particularmente problemático y las frases de Antoine y de Flore ilustran las tensiones inherentes a estos delicados pasos.

Pues duró... durante bastante tiempo fue sólo por escrito. Como.... como los dos primeros meses, diría yo, fue sólo por escrito.

J.C. : Y ¿cómo apareció la webcam?

Antoine : Poco a poco, a medida que la relación se estrechaba porque... no me veía diciéndole "hola, hace una semana que nos conocemos, pon la cámara, nos vemos y hablamos" (Antoine, 29 años, asalariado, usuario de Meetic). 
Al principio, sólo era por escrito... y después... después me invitó a la cam. Y la verdad que pareció una falsa manipulación. Él clicó en la camarita que hay en la parte de arriba. Y yo no sabía... o sea, cuando vi la invitación a ... a aceptar la webcam, acepté en seguida. $Y$ después pensé "hablamos y nos vemos", es normal porque yo ya lo hacía con amigas y eso, ya la usaba la webcam. Así que no lo pensé. Y después cambio de opinión, se dio cuenta y me dijo "ah, vaya, me acabo de dar cuenta de lo que acabo de clicar." Yo qué sé. Nunca más le volví a decir nada sobre eso, si era cierto o no, pero en todo caso no la puso en seguida, tardó unos días hasta que se decidió a conectarla (Flore, 24 años, estudiante, usuaria de Meetic).

En situaciones particulares, la webcam puede ser una manera de disminuir el sentimiento de riesgo precedente a un encuentro, ya que los contactos sucesivos dan lugar a información siempre más precisa y "exacta". La imagen en movimiento parece que hace más difíciles los engaños y las manipulaciones. “Un video en directo (al contrario que una imagen pregrabada, no interactiva) podría hacer más difícil de manera significativa el hecho de describir de forma convincente ciertos tipos de auto representaciones falaces. ${ }^{24}$ De hecho, en el siguiente extracto, la webcam es claramente para Denis un modo de paliar el riesgo excepcional que representa la arriesgada apuesta de ir a pasar una semana entera con una persona que no ha visto nunca en vivo.

Me fui a Córcega a ver a una amiga de allí, era un encuentro por gusto, pero... eh, también era un riesgo. Me invitó por Navidad, bueno por... sí, por Navidad, pasé ahí las navidades. Fue un riesgo... porque... no es fácil ir a casa de alguien que no conoces en persona (...), la podríamos haber cagado y podría haber habido mucho reproche por una parte y por la otra, y también me habría sentido incómodo de saber que no le gustaba, o que ella no me gustaba a mí, pero... bueno, ya sabíamos a lo que nos exponíamos... (...)

J.C. : Entonces ¿es un riesgo aceptado por ambas partes, como si fuera parte de todo esto?

${ }^{24}$ Donath, 2003, p.44. 
Denis : Bueno, pues para esta chica de Córcega (...) sí, estábamos en el mismo punto, para ambas partes era lo mismo, sabíamos que... que había un riesgo, de hecho no teníamos ni miedo, no teníamos miedo ninguno de los dos.

J.C. : ¿Hablasteis un poco de ello?

Denis : Sí, bastante, bastante.

J.C. : Y ¿no os llamasteis tampoco antes de veros?

Denis : Sí, nos llamamos, y... también teníamos la webcam, conque de todas formas nos conocíamos bastante bien, sabes...(...) Sí, todo nos tranquilizó, la webcam, la voz... hablamos de nuestra vida cada uno, ya fuera por teléfono o por el chat, nos conocíamos mucho (...) así que estábamos completamente tranquilos (Denis, 45 años, asalariado, usuario de Meetic).

\section{Complementación de las herramientas y sus "territorios"}

Una vez han entrado en juego nuevas formas de contacto para equipar la relación, se complementan las unas a las otras y apoyan de manera distinta a la relación en función de las propiedades de cada una. El aumento de los contactos significa un crecimiento del compromiso, y un aumento proporcional de las ocasiones de entrar en contacto. Las relaciones se "desplazan" de la presencia única en internet a contextos múltiples a los que el teléfono móvil da acceso, por ejemplo. Poco a poco las relaciones ya no están confinadas a un espacio estrecho de sociabilidad, sino que se desplazan para ocupar un lugar cada vez mayor en la vida cotidiana de los actores. Así, se autonomizan poco a poco del marco inicial para convertirse en relaciones "como las demás". Desarrollando el carácter "entrelazado" de las diferentes formas de contacto, Beaudoin, Cardon y Smoreda muestran asimismo que "la historia de cada relación se apoya sucesiva o paralelamente en los distintos soportes, y cada uno se utiliza con un significado específico en la gestión de las relaciones. Cuanto más íntima es la relación, más se multiplican las herramientas empleadas en ella." 25 Estos pasos aparecen como "situaciones que permiten la atribución no ambigua de motivaciones positivas al comportamiento de la pareja". ${ }^{26}$ Para los implicados, conlleva una voluntad por parte del otro de avanzar y de

${ }^{25}$ Cardon, Smoreda \& Beaudouin, 2005, p.110. 
comprometerse más; dichos pasos desempeñan pues un papel fundamental en la construcción de la confianza, que aumenta alimentándose de este tipo de juicios con respecto al otro y a sus motivaciones.

Desde el 27 de junio, mi relación electrónica con ELEA se amplió. ELEA empezó dándome la sorpresa de enviarme un primer sms durante mi fin de semana en familia, lejos de Internet, para mostrarme que pensaba en mí (un sábado noche es más gratificante aún). Y este tipo de pequeñas atenciones continuaron durante toda mi estancia en Marsella. Yo no estaba acostumbrado a demostraciones de interés y de deseo por su parte porque siempre estaba muy evasiva. Noté claramente una mejoría en nuestros contactos después de cada llamada telefónica. Era como si yo me hiciera más real, más accesible, dejé de ser un muñeco virtual, me formé en su imaginación (Anadema).

La relación adquiere un espesor y una consistencia más importante a medida que se suceden los contactos y que se diversifican, y lo mismo pasa con los "territorios" a los que el otro ha ido accediendo poco a poco. Al meterse suavemente en el universo "desconectado" de su pareja, el actor deja de existir solamente en la red para volverse un ser completo, que compite con actividades concretas y ya no sólo con los "adversarios" virtuales, tal y como nos lo muestra este último extracto. Los testimonios siguientes nos muestran a su vez cómo la cantidad de contactos distintos llevados a cabo en una relación permiten al actor, por una parte, definir la consistencia de una relación, pero también definir de manera más precisa al otro debido a la multiplicación de los contactos, lo que permite la diversidad de los formatos de interacción. Los contactos que sostienen la relación y su variedad son elementos importantes de definición de la relación.

En general, empezaba a considerar el plan como bastante concreto cuando habíamos chateado una o varias veces, intercambiado e-mails y números de móvil, y a veces hablado por teléfono algunos minutos (Nick).

Tenía toda la sensación de conocerla porque de hecho... al ver sus reacciones por escrito, uno empieza a... a percibir a la vez el carácter de la persona, también su forma de reaccionar a ciertas cosas porque yo

\footnotetext{
${ }^{26}$ Miller \& Rempel, 2004, p.696.
} 
tampoco estaba... en plan sumiso, a veces la chinchaba, y cosas así. Al verla también por la webcam empecé a percibir también sus reacciones, su comportamiento (Antoine, 29 años, asalariado, usuario de Meetic).

De la misma manera, cuando el recorrido desemboca en un encuentro físico, las comunicaciones mediatizadas no desaparecen, por el contrario permanecen muy presentes en el mantenimiento del vínculo. Si las relaciones llegan a autonomizarse del universo mediático en el que se iniciaron, es interesante notar que la tecnología queda impresa y se conserva en esta relación aún cuando ya se ha cruzado la barrera del encuentro físico.

[Una vez que el encuentro a tenido lugar y que la relación amorosa física ha comenzado] Se crea una costumbre e incluso una necesidad después. O sea, que no hay... no diría que hay una necesidad pero sí una carencia en cierta manera. (...) creo que es por eso por lo que la transición ha sido bastante viva, porque... había... eh... había una falta de ... de esta costumbre de llegar a casa, conectarse al Messenger, ver si ella estaba conectada, sí, está ahí, pum, conecto la cámara y hablamos. Lo hemos ido haciendo así, y después... poco a poco, como teníamos nuestros teléfonos, nos llamábamos y... después, la transición sucedió de manera natural (Antoine, 29 años, asalariado, usuario de Meetic).

Ling muestra cómo una situación de incertidumbre en una relación conduce a los adolescentes a preferir los mensajes escritos a las delicadas e incómodas conversaciones telefónicas. De esta manera, cuenta que "el móvil va más allá de la confirmación de las relaciones existentes. Los mensajes de texto han permitido el comienzo de nuevas relaciones. La naturaleza asincrónica de estos mensajes permite a una pareja nueva descubrirse puntos de interés y poner en marcha su relación de forma más apacible"27. El contacto escrito, también en nuestro caso, se emplea con mucha frecuencia para decidir el estado de los propios sentimientos y de la relación, inmediatamente o poco tiempo después de un encuentro físico. Cuando las cosas no está claramente establecidas, los actores, preocupados por clarificar la situación y por saber lo que el otro piensa de ellos y de la posible relación en proceso, solicitan su punto de vista o la confirmación de la calidad del momento pasado por el envío de un mensaje que informa sobre uno y demanda una reacción supuestamente aclaratoria sobre el estado de ánimo del otro.

${ }^{27}$ Ling, 2002, p.288 
Desde el jueves, Iséa y yo batimos récords de silencio: dos SMS cada uno en total jen 5 días! Cuando estábamos acostumbrados a 2 horas mínimo de chat al día desde hace 1 mes, el cambio se hizo notar radicalmente.

Me esperaba al menos un mensajito suyo el viernes, para tranquilizarme y confirmarme que nuestro día juntos no había estropeado nada. Y en fin... nada, vacío total... ni siquiera se conectó al Messenger en todo el día (extracto del blog de Anadema).

Sin embargo, no todas las relaciones se prestan a dar comienzo con estos caminos, a veces muy largos. Efectivamente, los objetivos distintos ( $y$ a menudo de menos compromiso) pueden conllevar caminos muy cortos. Así, si dos usuarios que se conectan a la página web para encontrar pareja sexual rápidamente, tienen los objetivos claramente definidos entre ellos, y se crea un sentimiento de confianza mínimo, pueden ahorrarse algunas etapas, algunas formas de contacto o el hecho de instalarse en un régimen relacional a largo plazo. El objetivo aquí ya no es entablar una relación afectiva estable, sino encontrar un compañero para tener sexo recreativo, por tanto los imperativos, así como las garantías a obtener, no son los mismos. Una atracción física y cierta seguridad son más fáciles de juzgar y probar que una complicidad intelectual real y afectiva, y sus pruebas correspondientes son más simples y rápidas de superar.

De la misma forma, parece que los desengaños sucesivos en el momento del encuentro físico empujan a los usuarios experimentados a precipitar el momento de la confrontación física más de lo que lo hacían al principio. De esta manera, se aseguran con suficiente antelación una "compatibilidad" física ahorrándose contactos largos en los que ambos fantaseen con una relación que finalmente no podrá ver la luz. Es evidente que es menos doloroso finalizar una relación en la que uno se ha implicado muy poco, que desmontar un vínculo fuerte pero que no sabe encontrar los elementos que le permitan perdurar en el tiempo. Este momento específico no se detalla aquí, y sin embargo es fundamental y en lo que se refiere a las representaciones también contribuyen a variar la duración de los caminos de confianza, ya que debe concluir el camino y cerrar el destino de los amantes potenciales. 


\section{5. la tecnología como apoyo para mantener las relaciones}

Las webs de relaciones personales ofrecen poner en contacto potencialmente a una cantidad muy importante de personas. Esto tiene consecuencias directas sobre la utilización de las herramientas en el momento de la toma de contacto, y también veremos que a su vez desempeña un papel importante en el mantenimiento de los vínculos iniciados.

Los usuarios emplean con mucha frecuencia el volumen de contactos potenciales puestos a su disposición para multiplicar los contactos y procurar maximizar sus posibilidades de alcanzar sus fines, como Nick, que aplica su "lógica cuantitativa" y su "estrategia de relaciones masivamente paralelas".

Sin embargo, puede resultar difícil, incluso imposible, mantener estos vínculos de forma satisfactoria, no "perder el hilo" de las relaciones sin ayuda externa o sin un sistema de ayuda para la memoria. Como dice Nick, muy pronto se hace "difícil recordar en 2 segundos todos los detalles de cada persona, cuando se está en una relación virtual o real con 20 ó 30 al mismo tiempo". Para responder a estas necesidades, la técnica resulta una vez más de gran ayuda. Si se admiten la pluralidad de contactos y relaciones y excusan cierto número de "lagunas mentales", el signo mínimo de interés por el interlocutor parece ser el hecho de recordar los elementos importantes que hasta el momento hayan intercambiado. Sin embargo esto no es fácil, y requiere la activación de dispositivos de externalización de la memoria más o menos expertos. Los artefactos cognitivos ${ }^{28}$ empleados por los usuarios se utilizan para asegurarse de no ser descubiertos en los numerosos y concurrentes compromisos.

A veces meto la pata con los nombres, pero... pienso qué le vamos a hacer. Yo lo vivo así, no quiero anotarlo en un papel. Antes lo apuntaba en un papel. Algunas veces apunto en el papel porque... me tengo que acordar del nombre al menos... eh... si no, qué mala impresión (Denis, 45 años, asalariado, usuario de Meetic).

Las mismas webs facilitan los procesos de memorización activando herramientas que permiten memorizar, almacenar, y después recordarte a las personas, los objetos o las informaciones relacionadas con ellas. La web de Meetic registra por ejemplo los recorridos de usuarios de ficha en ficha, creando listas de visitantes y

\footnotetext{
${ }^{28}$ Norman, 1993.
} 
de contactos pasados. También es posible crear "listas de amigos", permitiendo en cualquier momento encontrar a las personas con las que se inició un contacto. No obstante, estos dispositivos pueden resultar insuficientes. Los usuarios tienden a emplear aún más la capacidad de memoria disponible para cubrir el número de contactos. De esta forma Nick crea verdaderos archivos donde almacena gran cantidad de información. "Cada vez que chateaba con una chica archivaba todo el texto de nuestra conversación. También guardaba sus fotos y almacenaba todo eso en mi ordenata, en una carpeta especial". Esta externalización de la memoria le permite en cualquier momento recordar la información relacionada con una u otra usuaria. Las herramientas de las que dispone y que utiliza activamente con este fin, constituyen para él un almacén de conocimiento en el que se apoyan sus definiciones (equipadas) de situación, condición sine qua non del mantenimiento simultáneo de un número importante de relaciones.

Esta práctica de almacenamiento permite también al usuario reflexionar sobre los contactos pasados. Al estar desligado de la presión del instante, puede tomarse su tiempo para reflexionar. Estas formas de memorización también son señal de una implicación relacional específica. Así, Óscar nos explica que grabó en su ordenador los mensajes con su compañera privilegiada del momento, por un lado porque los mensajes eran tan largos que hacían difícil responder sin omitir nada en caso de no disponer del mensaje de origen para asegurarse; y por otro lado, porque ese procedimiento le permitía crear un "histórico" que "le gustaba" tener y además le podía "servir".

Una vez que acumulé bastantes contactos, pude mirármelo todo tranquilamente, releer nuestros chats, y eso me daba otra visión de las cosas, menos febril que en vivo. Eso también me permitía decidir qué nivel tenía ganas de cruzar a corto plazo, es decir, a qué chicas tenía ganas de conocer en persona (Nick).

La personalización de las herramientas permite a los usuarios poner en marcha atajos cognitivos que les permiten gestionar de manera más eficaz sus relaciones. La configuración de tonos en el móvil, los caracteres especiales delante del nombre en función de la naturaleza de la relación, el agrupamiento de los interlocutores en diferentes categorías, son algunos de los medios disponibles para el usuario para darse puntos de apoyo en la acción y hacer más simple y eficaz el mantenimiento de los vínculos iniciados. 
En la agenda de mi móvil todos los nombres de chica "del momento" tienen antes una estrella, lo que las coloca al final de la agenda, todas juntas, y accesibles super rápido poniendo sólo * en el teclado. Las que ya no veo o que he dejado un poco de lado en ese momento, tiene una $Z$ antes del nombre, lo que las coloca al final de la lista de las chicas "activas". Evidentemente, a menudo ocurre que un nombre pasa de una categoría a otra, según el humor del momento (¡del mío o del suyo!). ¿Que se hace la remolona y no tiene pinta de que podamos quedar pronto? No me voy a empeñar, así que le pongo una $Z$ delante del nombre y pasa a la lista no prioritaria, para que todos los nombres con la estrella queden fácilmente accesibles y no contengan "causas perdidas" (Nick).

De esta forma, Nick ha puesto parámetros en su teléfono y ha creado grupos de contactos para poder gestionar los derechos de entrada y las prohibiciones a una $u$ otra de las chicas de su agenda, sin intervenir directamente en la situación. De esta manera, en un instante y con el tono de llamada adecuado, puede saber qué tipo de interlocutor intenta contactarle. También puede bloquear las llamadas de sus otras conocidas cuando se encuentra en compañía de una de sus conquistas. Su dominio de la herramienta le permite pues mantener la relación de manera mucho más fácil evitando al máximo los riesgos que conllevan las relaciones amorosas simultáneas. Las situaciones y las relaciones están tipificadas y el parametraje de su teléfono viene configurado en base a estos dos tipos. Los tipos de relación se clasifican en los grupos de contactos, que delimitan los contornos de redes más o menos compatibles con las diferentes situaciones en las que Nick se puede encontrar. Los tipos de situaciones vienen clasificados en modos que activan funciones específicas según los distintos grupos de contactos, por tanto, los distintos tipos de interlocutor. La tarea de asegurarse de que una relación "clandestina" no irrumpirá en una situación donde él se encuentre con su novia oficial, se anticipa y se delega ${ }^{29}$ al dispositivo, que garantiza que los riesgos están controlados, siempre y cuando Nick haya pensado en activar el modo apropiado.

${ }^{29}$ Latour, 2006. 
He creado varios grupos de contacto en mi móvil: todas las chicas con las que suelo quedar con más o menos frecuencia están guardadas en el grupo "GURLZ", que tiene un tono específico (la música del anuncio de DIM: sí, me recuerda de inmediato a unas braguitas, ¡así que es coherente y mnemotécnico!).

También he creado un grupo de contactos "G-LOVE", en el que he puesto a mi niña del momento, mi "actual", con un tono específico. Como es evidente, este grupo sólo puede contener un nombre. ¡Y ya es bastante difícil así!

Finalmente, el último grupo que he creado es "G-NOW", que utilizo temporalmente para filtrar a todas las chicas, incluido mi "actual", excepto con la que voy a pasar la noche, y que meto temporalmente en este grupo.

Ahora todos los números de chicas estás clasificados en un grupo de contactos y los puedo filtrar con los MODOS.

He programado varios modos en mi móvil, que definen qué llamadas pueden entrar, y lo que pasa de manera general (tonos, mensajes, etc).

Combinando todo esto, me aseguro de que ninguna persona "inapropiada" me va a molestar en un mal momento.

Cuando estoy con mi niña, pongo el modo "G-OFF" que bloquea todas las llamadas entrantes de chicas del grupo "GURLZ", y las envía directamente al buzón de voz. Y tengo programado el buzón de voz para que no me llame, y para que no me avise cuando recibo un mensaje. Maxi discreción si alguien me manda un mensaje de texto un poco caliente...

Así no me arriesgo a que me moleste una llamada o un SMS de otra mientras estoy con ella. El resto de llamadas entran, los amigos, el curro, la familia... pero ninguna chica del grupo "GURLZ".

Cuando tengo una cita inminente con una tía que puede quedar conmigo, la paso temporalmente del grupo "GURLZ" al grupo "G-NOW": esto bloquea a todas las llamadas "GURLZ" (o sea, a todas las chicas), y también a mi nena del grupo "G-LOVE", pero deja entrar sus llamadas, 
para que sólo ella pueda localizarme (por ejemplo para pedirme una clave, o decirme dónde encontrarme con ella) (Nick).

Hemos visto cómo el hecho de salir de la "zona internet" puede constituir un verdadero juego relacional en la formación del vínculo. De hecho ya lo es en lo que se refiere a su mantenimiento. Los actores están sensibles y atentos a las "pequeñas señales" con las que las herramientas múltiples les permiten dirigirse los unos a los otros, en los diferentes contextos y en diferentes momentos del día. Mantener el vínculo pasa por el uso conjunto y simultáneo de estos soportes, tal vez con mayor razón cuando inicialmente se creó este vínculo por medio de estas herramientas de la comunicación a distancia. El extracto que sigue nos muestra asimismo cómo esta modalidad "conectada" ${ }^{30}$ de mantenimiento del vínculo puede conformar una dimensión estratégica, según el sentido que tal acción suponga para los actores. Nick ha comprendido que las mujeres de las que se ocupa de contactar por medio de las múltiples herramientas a su disposición, interpretarán tales signos como un deseo por su parte de mantener el vínculo y de comprometerse en la relación. Él pone a su servicio los conocimientos y calificaciones que extrae de los usos de otros. Haciendo esto, pretende dominar estratégicamente las impresiones que él produce y las opiniones que genera en sus encuentros.

Una vez escuché una expresión que me encantó sobre ligar y las chicas: "para pescar langostas, hay que poner una red". Y vaya si es verdad.

La red son las pequeñas atenciones. Y la tecnología moderna es ideal para eso. Por ejemplo: un sms de vez en cuando para que se acuerde de ti, una llamadita "desinteresada" (al menos a corto plazo) para saber de ella, un e-mail corto pero amistoso para dar señales de tanto en cuando.

Es mucho más fácil volver a acostarte con una chica que tiene la impresión de que no hemos roto el hilo desde la última vez, gracias a algunos contactillos sin importancia. Al menos, no te puede salir con que "todo lo que te interesa es llevarme a la cama". Aunque a menudo sea exactamente eso. Mantener contactos esporádicos pero regulares elimina/borra considerablemente este riesgo y casi te lleva a parecer

\footnotetext{
${ }^{30}$ Licoppe, 2002.
} 
alguien realmente interesado en su vida fuera del perímetro de una cama (Nick).

Para terminar nuestro análisis, querríamos detenernos algunos instantes en una paradoja que presenta el análisis de estos usos. Los usuarios, en cierta manera, parecen transformarse en expertos de la cualificación y de la selección. Las NTIC* acentúan la reflexión de un actor que se transforma en profesional de la cualificación. También contribuyen, entre otras cosas, a visualizar sus preferencias, aumentando por lo mismo la reflexión y la racionalización de los usos. No obstante, hacemos hincapié en que esta racionalización de la elección conduce a menudo a situaciones de auténtico desencanto de usuarios hastiados y cínicos. Mientras que los modos razonados de apareamiento deberían permitir a los usuarios de estos portales encontrar con más facilidad a la "persona adecuada", parece que estas empresas generan con bastante frecuencia efectos perversos obligando a los usuarios a asumir papeles de los que no se saben desembarazar y que contribuyen por lo tanto a su insatisfacción. El "papel" particular que los usuarios de las webs de encuentros asumen en el objetivo de iniciar o de mantener estas relaciones, se aleja, en mayor o menor medida, de lo que son en los universos desconectados de interacción. Tales papeles presentan sin embargo una relativa irreversibilidad. De hecho, a menudo es difícil dar marcha atrás, por ejemplo, para iniciar una relación a largo plazo cuando en un principio sólo se había planteado como una relación lúdica o de distracción. La reflexión sobre los usos que presentamos aquí parece pues dudosa. El actor racional a cuyo perfil nos enfocamos debería saber poner los límites de los usos que con frecuencia no saben colmar sus expectativas.

Nuestras observaciones nos muestran que las herramientas se emplean activamente para reducir una parte de la incertidumbre relacionada con el hecho de entablar una relación con desconocidos. Si se utilizan, el riesgo está en parte dominado. Sin embargo, debemos citar el concepto de riesgo. Es un sentimiento aceptado por los actores ya que son desconocidos entre ellos y la relación está por construirse en su totalidad. A partir de ahí, esta modalidad relacional permite la utilización de las informaciones generadas por dispositivos que, por la misma razón, legitiman su uso. El cálculo y la racionalización en relación al otro aparecen pues como elementos razonables del "descubrimiento equipado". Este descubrimiento progresivo utiliza también los dispositivos y su encadenamiento de cara a constituir procesos de compromiso y de reducción de los riesgos graduales. Hemos visto no

* (N.T. Nuevas Tecnologías de la Información y la Comunicación). 
obstante que a medida que la relación progresa, la prudencia da lugar a la confianza. Poco a poco, este proceso pasa por el abandono o el desapego progresivo de los mediadores, concediéndose prudencia en provecho del acercamiento físico, consecuencia y signo de la confianza que los actores se profesan. El nivel de implicación, efectivo pero también y sobre todo potencial y deseado, condiciona pues en parte la extensión del camino. Ambas partes se implican en la relación que construyen juntos y progresivamente van instaurando un juego conjunto que emplea, para perseguirse, repetirse y eventualmente perennizarse, formas típicas de inversión en las que éstas relaciones se acercan a medida que abandonan los territorios donde comenzaron, colonizan otros nuevos y terminan en ocasiones por convertirse en relaciones "como las demás" que, ya que la confianza se ha podido establecer, merecen los esfuerzos necesarios para la continuidad de la relación.

Es alguien en quien tengo total confianza. Así que la relación que destaco realmente es la que... la que protejo y querría conservar indefinidamente. $Y$ creo que es la aportación más grande que... que saco de mi inscripción en Meetic (Marie, 22 años, estudiante, usuaria de Meetic).

El estudio de la utilización de estas webs nos ha permitido identificar algunos de los elementos en tensión durante el proceso de inicio de una relación y el de la construcción de esos "caminos de confianza". Así hemos podido estudiar los múltiples equipos de esta construcción progresiva de confianza que se da en especial por medio del "test" de los dispositivos en sí mismos y la puesta en marcha de relaciones procesadas, gracias a las herramientas y al compromiso progresivo que permiten. Si extendemos un instante nuestra reflexión a las relaciones en general, parece que una vez más, las nociones de riesgo y de incertidumbre ${ }^{31}$ son centrales, y más aún cuando estos inicios de relación implican a desconocidos, el anonimato de Internet puede dar lugar a provocar estos sentimientos de peligro relacionados con la confianza ${ }^{32}$. Parece que los inicios de las relaciones de las que hablamos aquí revelan ambos procesos. Si la situación implica un riesgo, si los actores pueden anticipar las consecuencias negativas de la situación o de sus acciones, es posible (para ellos, tanto como para el mediador) poner en marcha

\footnotetext{
${ }^{31}$ Knight, 1940.

${ }^{32}$ Henderson \& Gilding, 2004.
} 
sistemas de seguridad que les proteja contra estos riesgos eventuales. ${ }^{33}$ Así, el intercambio comercial, por ejemplo, ofrece observar una situación en la que tales sistemas pueden ser activados. Y de hecho, lo son: sistemas de reputación, reembolso en caso de abuso de parte de uno u otro de los actores, son algunos de los sistemas institucionalizados con la posibilidad de definir tanto los objetivos como los medios de su cumplimiento. Cuando la situación implica incertidumbre, como es el caso en las webs de encuentros amorosos, los actores no pueden definir con precisión qué es lo que les puede llevar a decepcionarse ni las consecuencias negativas eventuales de sus actos o de los de sus parejas. En base a esto, la institucionalización de los medios de protección es imposible. Hemos constatado cuáles pueden ser entonces las medidas de protección a pesar de la ausencia de un marco preconstruido de seguridad. Los actores "apañan" maneras de reducir progresivamente la incertidumbre respecto a su pareja, obteniendo cada vez más información que les permita comprometerse, efectuando para ello juicios que se adapten a sus necesidades de conocimiento. Los procesos de protección difieren pues de unen cada modalidad relacional y de un objetivo a otro, así como también difieren las formas de confianza iniciadas y por medio de consecuencias, la duración del camino de confianza. Sea como sea, tales modalidades relacionales ilustran una vez más la voluntad de reducir el riesgo. Esta voluntad está fuertemente equipada con los dispositivos que permiten la activación de estrategias de gestión de los compromisos y de los riesgos que implican. Así, se valora la racionalización de los procesos de vinculación. Efectivamente, "una reducción de los riesgos, sumado a evitar el cierre de las opciones es todo lo que queda de la elección racional en un mundo de ocasiones fluidas, con valores cambiantes y reglas eminentemente instables; las cibercitas, contrariamente a la delicada negociación de los compromisos mutuos, satisfacen a la perfección (o casi) estos nuevos criterios de elección racional ${ }^{34}$.

Aunque el riesgo y la incertidumbre se evitan todo lo posible en numerosos casos, parece, no obstante, que aceptar comprometerse a pesar de lo que queda en la sombra, es la condición sine qua non para que los objetivos relacionales se alcancen. Así pues, la figura de la confianza tal vez se relega a ser reemplazada por la de la prudencia ${ }^{35}$, que corresponde al problema práctico que los usuarios de tales

\footnotetext{
${ }^{33}$ Licoppe, Pharabod \& Assadi, 2003.

${ }^{34}$ Bauman, 2004, p.84.

35 Trompette (2003) utiliza este término para designar la actitud de las parejas inicialmente desconocidas entre sí que deben construir progresivamente una relación de confianza.
} 
sitios tienen que resolver. Estos últimos desean alcanzar un objetivo, más o menos preciso. Para ello, entran en contacto con desconocidos por medio de un dispositivo que les proporciona cierto número de garantías pero que no puede en ningún caso reducir totalmente el riesgo. Por lo tanto, tienen que comprometerse aceptando el riesgo y/o esta incertidumbre restantes. Como los negociadores que trata Bourque, "el principal dilema que confronta [el usuario] es una dosis hábil de confianza y de prudencia, ya que la confianza incondicional puede hacerle renunciar a ventajas para mantener la relación de cooperación, y la falta de confianza puede impedir la implementación de soluciones que procuren beneficios mutuos" ${ }^{36}$. La noción de "serendipia" nos permite concebir este riesgo asumido por los actores y anteponer el carácter emergente de los objetivos y de los caminos relacionales. Tal y como remarca Catelin, "la serendipia es efectiva a partir del momento en que, buscando algo y habiendo encontrado otra cosa, uno reconoce que lo que ha encontrado es más interesante o tiene más importancia que lo que estaba buscando." ${ }^{37}$ Saber dejarse sorprender y comprometerse en las relaciones que no esperábamos especialmente o que no estaban previstas, parece ser una nueva capacidad confinada en el marco de estos dispositivos de inicio de relación. La toma de riesgo está enmarcada (de manera más o menos acentuada, en función de la posible institucionalización de los objetivos y de su medio de cumplimiento) y es justamente esta toma de riesgo la que está racionalizada, al menos en parte, por y gracias al mediador. La prudencia, la atención a los signos que permiten construir juicios, es una solución práctica a los problemas que introduce el contexto de inicio de relación. Óscar resume en su proceso diciéndonos: "no tenía ganas de... de embarcarme en una historia en la que tuviera que asumir riesgos." Esta frase resume relativamente bien la actitud general hacia tales los dispositivos. Sin embargo, esta prudencia está destinada a evolucionar por medio de los mecanismos detallados con anterioridad para transformarse progresivamente en una confianza que se acerca a una confianza rutinaria ${ }^{38}$, mucho menos reflexiva y ya no tan cuestionada. Esta evolución puede ser considerada entonces como el signo del "éxito" del inicio de la relación que ha sabido "extraerse" de su contexto de origen para autonomizarse y convertirse en una relación normal. Las herramientas, que han sido los mediadores, deben acabar por desaparecer para que la relación que ha dado comienzo gracias a estos entornos pueda ser considerada como un éxito, aunque se conviertan a partir de entonces en

\footnotetext{
${ }^{36}$ Bourque, 1999, p.284.

${ }^{37}$ Catelin, 2001, p. 365.
} 
elementos ordinarios para mantener el vínculo. Sin embargo, aunque se supone que tienen que desaparecer, eso no impide que los actores los utilicen para construir un camino razonado y prudente donde se concedan confianza y la obtengan paso a paso.

\section{Bibliografía}

Allan, G. 1979. A sociology of friendship and kinship. London, Allen \& Unwin

Andrejevic, M. 2005. The Work of Watching One Another: Lateral Surveillance, Risk and Governance, Surveillance and Society, vol. $2 n^{\circ} 4$ p.479-497.

Axelrod, R. 1992. Donnant-donnant: une théorie du comportement coopératif. Paris, O. Jacob.

Baier, A. 1986. Trust and antitrust, Ethics, vol. $96, n^{\circ} 2$ p.231-260.

Bauman, Z. 2004. L'amour liquide: De la fragilité des liens entre les hommes, Rodez, Éd. du Rouergue.

Bidard, C. 1997. L'amitié un lien social, Paris, La découverte.

Blau, P.M. 1964. Exchange and power in social life, New York, J. Wiley

Bourque, R. 1999. Confiance et Négociation, in Thuderoz C., Mangematin, V., Harrisson D. (eds.) La confiance. Approches économiques et sociologiques, Paris, Ed. Gaëtan Morin, p.261-287.

Cardon, D., Smoreda, Z., Beadouin, V. 2005. Sociabilités et entrelacement des médias, in Ph. Moati (ed.) Nouvelles technologies et modes de vie, L'aube, «Petite bibliothèque du Crédoc », Paris, p.99-123.

Catellin, S. 2001. Sérendipité, abduction et recherche sur Internet, http://www.sfsic.org/sicnet/publications/actes-01/cate-01.pdf

Donath, J.S. 2003. Etre réel, Sociétés, n79 vol, De Boeck université.

Fernandez, B. 2003 Confiance et méfiance dans le rapport à l'altérité asiatique: Le cas de l'experience d'expatriés en Chine in Mangematin V., Thuderoz C. (eds.) Des mondes de confiance. Un concept à l'épreuve de la réalité sociale, Paris, CNRS ed., p.86-98.

Ferrand, A. 2007. Confidents. Une analyse structurale de réseaux sociaux, Paris, L'Harmattan

Gomez, P.-Y., Korrine, H., Masclef O. 2003 Alliance stratégique et construction de la confiance: le cas Renault-Nissan, in Mangematin V., Thuderoz C. (eds.) Des mondes de confiance. Un concept à l'épreuve de la réalité sociale, Paris, CNRS ed., p.203-218.

${ }^{38}$ Luhmann, 2006, p. 26 
Grossetti, M. 2004. Sociologie de l'imprévisible. Dynamiques de l'activité et des formes sociales, Presses Universitaires de France, Collection «Sociologie d'aujourd'hui ».

Grossetti, M. 2005, Where do social relations come from? A study of personal networks in the Toulouse area of France, Social networks $n^{\circ} 27$, Elsevier. p.289300.

Grossetti, M., Godart, F. 2007. Harrison White : des réseaux sociaux à une théorie structurale de l'action, SociologieS,

http://sociologies.revues.org/document233.html

Guillaume, C., Uhalde, M. 2003 Confiance et intervention sociologique en entreprise in Mangematin V., Thuderoz C. (eds.) Des mondes de confiance. Un concept à l'épreuve de la réalité sociale, Paris, CNRS ed., p.45-56.

Henderson, S., Gilding, M. 2004. 'I've never clicked this much with anyone in my life' : trust and hyperpersonal communication in online friendships, New Media and Society vol.6 (4) p.487-506.

Illouz, E. 2006. Réseaux amoureux sur internet, Réseaux vol.24 n¹38, Hermès, Paris, p.243-268.

Knight, F. 1940. Risk, Uncertainty and Profit, The London School of Economics and Polical Science, Londre.

Latour, B. 2006 (1993). Petites leçons de sociologie des sciences, Paris, La découverte.

Licoppe, C. 2002. Sociabilité et technologies de communication, Réseaux vol. 20 $n^{\circ} 112-113$, Hermès, Paris, p. 173-207.

Licoppe C., Pharabod A.-S., Assadi H. 2003. Contribution à une sociologie des échanges marchands sur Internet, Réseaux, vol. 21 n¹16, p.97-140.

Ling, R. 2002. L'impact du téléphone portable sur quatre institutions sociales, Réseaux, vol. $20 n^{\circ} 112-113$, p.275-312

Lorenze, E. 1996. Confiance, contrats et coopération économique, in Sociologie du travail, $n^{\circ} 4$, p. 487-508.

Luhmann, N. 2006. La Confiance. Un mécanisme de réduction de la complexité sociale, Paris, Economica ed.

Miller, P., Rempel, J. 2004. Trust and Partner-Enhancing Attributions in Close Relationships, Personality and Social Psychology Bulletin, vol. $30 n^{\circ}$ 6, p.695-705

Möllering, G. 2001. The Nature of Trust: from Georg Simmel to a Theory of Expectation, Interpretation and Suspension, Sociology (35.2) p.403-420.

Möllering, G. 2005. The Trust/Control Duality: An Integrative Perspective on Positive Expectations of Others, International Sociology 20 (3), p.283-305.

Nooteboom, B. 2006, Introduction, in Ogien A., Quéré L. (eds.) Apprendre à faire confiance, Paris, Economica ed., p.63-85. 
Norman, D.A. 1993. Les Artefacts cognitifs. in Conein B., Dodier N., Thevenot L. (eds.) Raisons pratiques $n^{\circ} 4$. Les objets dans l'action, p.15-34. Paris, Edition de l'Ecole des Hautes Etudes en Sciences Sociales.

Quéré, L. 2001. La structure cognitive et normative de la confiance, Réseaux vol.19 $n^{\circ} 108$, Hermès, Paris, p. 125-154.

Quéré, L. 2006. Confiance et engagement, in Ogien A., Quéré L. (eds.) Les moments de la confiance. Connaissance, affects et engagements, Paris, Economica ed., p.117-142.

Simmel, G. 1999. Sociologie. Etudes sur les formes de la socialisation, Paris, PUF.

Sztompka, P. 1999. Trust: A Sociological Theory, Cambridge, Cambridge University Press.

Trompette, P. 2003 De la prudence... à la confiance, in Mangematin V., Thuderoz C. (eds.) Des mondes de confiance. Un concept à l'épreuve de la réalité sociale. Paris, CNRS ed., p.99-107.

White, H. 1992. Identity and Control: A Structural Theory of Social Action, Princeton, Princeton University Press

White H. 2002. Markets from Network : Socioeconomic Models of Production, Princeton, Princeton University Press 